\title{
The War against Coronavirus Disease 19 through the Eyes of Cancer Physician: An Italian and Indian Young Medical Oncologist's Perspective
}

These are unprecedented times, we are living in with an outbreak of a novel coronavirus, also known as severe acute respiratory syndrome coronavirus $2(\mathrm{CoV}-2)$, or $\mathrm{CoV}$ Disease 19 (COVID-19). By April 20"th as per the World Health Organization Data, COVID-19 as a pandemic has caused 2,407,414 cases, and 165,073 confirmed deaths in 213 different countries worldwide.

Elderly patients and those with comorbid illnesses with COVID-19 infection have poor outcomes. Cancer patients are immunosuppressed, and at an increased risk of COVID-19 infection and have worse outcomes as compared to the general population. The mortality rate of COVID-19 among oncology patients is about $20 \%{ }^{[1]}$ Young oncologists are guided by the national and international cancer societies through guidelines that are adapted during this pandemic for the safety of patients and physicians ${ }^{[2,3]}$ Patients with active cancer therapy including chemotherapy, immunotherapy, radiotherapy, and surgery are at a higher risk as compared to cancer survivors. ${ }^{[4]}$ Patients are not only worried about disease courses due to the lack of transport, inaccessibility to the hospital, and shortage of medications but also about the transmission of the virus to their relatives, friends, and caregivers. It is a challenging situation, as cancer patients are in a vulnerable situation, and physicians have to make difficult decisions due to the uncertainty. The number of registered cases of COVID-19 in Italy was 162,488 as of April $14^{\text {th }}$, the third highest globally behind the United States and Spain, according to the data of Istituto Superiore di Sanità. As Italy's death toll passed 18,279 on April $10^{\text {th }}$, the Italian government announced the lockdown to be extended until early May. The deaths included more than 17,000 frontline health-care workers, who were in this war against the Novel Corona Virus. The Italian health-care system, known as Servizio Sanitario Nazionale, provided an immediate, efficient, and effective solution to this crisis. It is increasing intensive care unit capacity and recruiting doctors, nurses, and medical staff for the emergency $\mathrm{CoV}$ task force, which included retired doctors, medical graduates, and residents. Embracing the Hippocratic Oath, over 7000 retired doctors came to fight against this deadly virus. Standing by and watching are impossible for those who face pain every day, even if they are recent medical school graduates. They were all ready to go in the frontline fight against COVID, where the need is greatest, learning daily, as this crisis is a new experience even for specialists with 20 years of experience. Unfortunately, the number of doctors who have died of COVID-19 infection reached 121 as on April 15, 2020, according to the Italian doctors' federation Federazione Nazionale degli Ordini dei Medici Chirurghi e Degli Odontoiatri. The reasons include a shortage of personal protective equipment (PPE) and the lack of COVID-19 diagnostic kits.

The Italian Association of Medical Oncology (AIOM) with the boards of Academic Oncologists (COMU) and Oncology Unit Director (CIPOMO) suggested recommendations on cancer care during the COVID-19 crisis. The recommendations include delaying cancer treatments based on clinical status, prognosis, and tumor characteristics and reducing follow-up visits using online consultations to assess the patient's status. Many oncological institutions in Italy offer online psychological counseling services, as patients find it difficult to cope up during the lockdown and to reduce the patient visits to the hospital. Teleconferencing is a gamechanger in healthcare as tablets and smartphones connect patients with their loved ones. People of Italy had supported the health-care workers and staff in the COVID-19 fight.

As on April 20, 2020, the number of COVID-19-positive patients in India was 17,357, of which 13,938 were active, 2859 patients had recovered, and 560 had succumbed. The trends of COVID-19 in India were different as compared to the developed world. The reasons are still to be explored retrospectively. Several hypotheses include different strains of COVID-19 in different countries, the presence of malaria as an endemic disease, and universal Bacillus Calmette-Guérin vaccination in India. The Indian government has chosen to lockdown the entire country from March $20^{\text {th }}$ to prevent the spread. Cancer care in India continued with great difficulty despite the lockdown affecting the transport.

Guidelines both in general and for specific cancers were published by cancer societies in India such as Indian Society of Medical and Pediatric Oncology and Indian Cooperative Oncology Network, for the efficient utilization of resources in these challenging times and how to modulate practices balancing the risk-benefit ratio due to COVID infection and cancer-directed therapy. The key takeaways include weighing the risks and benefits of palliative chemotherapy against the risk of COVID infection, postponing nonurgent appointments, following up such patients with telemedicine, and decision to use antiangiogenic therapies and immunotherapy on a case-by-case basis. Medical education, including oncology updates was affected severely. Thankfully, several webinars and live online classes conducted by the editorial staff of the Indian Journal of Medical and Pediatric Oncology helped students to keep up with the continuing oncology updates. Several doctors and medical staff, including oncologists, got infected in the 
process of delivering care to COVID-19 positive patients and treating asymptomatic patients who had come for treatment. However, the fight is still on and being continued by thousands of doctors, despite the saddening death of some colleague doctors due to COVID infection. The reasons include the lack of PPE and limited testing. However, now the government has approved testing in private laboratories for COVID-19, allowing more testing in all suspected cases, asymptomatic high-risk contacts of a confirmed case, and all symptomatic health-care workers. $^{[5]}$ The main breakthrough that happened in the light of the pandemic in India is the introduction of telemedicine guidelines by the Health Ministry of India. This move was taken in the light of restriction of movement of patients making routine clinical visits difficult, and most importantly to decongest health-care system. This is particularly useful for patients who are on follow-up after the completion of treatment.

Empathy in cancer care has always been the backbone of the patient-physician communication, practicing which has been a challenge with masks on the face, and PPE masking the facial expressions. As oncologists, we have to support our patients more than ever by showing smiles through our eyes. The society also needs to be empathetic about health-care personal who are risking their own and their loved ones' lives in these difficult times to help the patients. Indian doctors have to face and fight just more than COVID pandemic that is ignorance and apathy of some people in the society. There were several reports of assaults on doctors, residents throughout the country, with the wrong impression that they are carriers of this virus. They were forcefully evicted from the rented houses and are boycotted in many housing societies. Doctors were stoned and had to shed blood when they went door to door for contact tracing. In Tamil Nadu, doctors who died of COVID-19 infection were refused burial by the general public, fearing the spread of $\mathrm{CoV} .^{[6]}$

In Italy, where one of the highest numbers of cases was reported, there was no assault on health-care workers. However, despite the pessimistic instances in India, the determination of cancer patients and the iron will of oncologists to care for patients resulted in the continuum of cancer care. One instance I faced was a 25-year-old young female who drove $800 \mathrm{~km}$ for her mother's treatment, chemotherapy for locally advanced breast cancer, clearing through 28 police check posts in the lockdown from the interior village in Uttarakhand. Another 65-year-old gentleman pedaled $140 \mathrm{~km}$ with his wife tied to his back, to prevent her from falling down, to reach Jawaharlal Institute of Postgraduate Medical Education and Research, Puducherry, for chemotherapy. Such heartwarming tales keep us inspired and continue cancer care during this deadly pandemic.

Learning to live with uncertainty during the COVID-19 crisis is the only way at this point. Compulsory quarantine with social distancing has disrupted daily life, but technology has helped people to connect worldwide. The coming months will pose further challenges in this crucial fight. Empathy and patient-centered care for health-care professionals are vital in these uncertain times. We shall never forget, this too, shall pass.

\section{Financial support and sponsorship}

Nil.

\section{Conflicts of interest}

There are no conflicts of interest.

\section{Maria La Mantia ${ }^{1}$, Venkata Pradeep Babu Koyyala}

${ }^{\prime}$ Department of Surgical, Oncological and Oral Sciences, Section of Medical Oncology, University of Palermo, Palermo, Italy, ${ }^{2}$ Department of Medical Oncology, Rajiv Gandhi Cancer Institute and Research Centre,

New Delhi, India

Address for correspondence: Dr. Venkata Pradeep Babu Koyyala,

Room: 3162, $1^{\text {st }}$ Floor, D Block, Rajiv Gandhi Cancer Institute and Research Centre, Sector-5, Rohini, New Delhi - 110 085, India. E-mail: pradeepbabu.koyyala@gmail.com

Submitted: 21-Apr-2020

Accepted in Revised Form: 28-Apr-2020

Published: 27-Jun-2020

\section{References}

1. Liang W, Guan W, Chen R, Wang W, Li J, Xu K, et al. Cancer patients in SARS-CoV-2 infection: A nationwide analysis in China. Lancet Oncol 2020;21:335-7.

2. American Society for Clinical Oncology. COVID-19 Patient Care Information. Available from: http://www.asco.org/asco-coronavirus-information/ care-individuals-cancer-during-covid-19. [Last accessed on 2020 Apr 20].

3. European Society for Clinical Oncology Guidelines. Cancer Patient Management during the Covid-19 Pandemic. Available from: http://www.esmo.org/guidelines/ cancer-patient-management-during-the-covid-19-pandemic. [Last accessed on 2020 Apr 20]. 
4. Hanping W, Zhang L. Risk of COVID-19 for patients with cancer. Lancet Oncol 2020;21:e181.

5. Indian Council of Medical Research Guidelines on COVID-19. Available from: https://icmr.nic.in/content/covid-19. [Last accessed on 2020 Apr 20].

6. Available from: https://www.thehindu.com/news/cities/chennai/ local-residents-protest-cremation-of-doctors-body-in-chennai/ article31331307.ece. [Last accessed on 2020 Apr 20].
This is an open access journal, and articles are distributed under the terms of the Creative Commons Attribution-NonCommercial-ShareAlike 4.0 License, which allows others to remix, tweak, and build upon the work non-commercially, as long as appropriate credit is given and the new creations are licensed under the identical terms.

For reprints contact: WKHLRPMedknow_reprints@wolterskluwer.com

\begin{tabular}{|l|l|}
\hline \multicolumn{2}{|c|}{ Access this article online } \\
\hline Quick Response Code: & Website: \\
& www.ijmpo.org \\
\cline { 2 - 2 } & DOI: \\
\hline
\end{tabular}

How to cite this article: La Mantia M, Koyyala VP. The war against coronavirus disease 19 through the eyes of cancer physician: An Italian and Indian young medical oncologist's perspective. Indian J Med Paediatr Oncol 2020;41:305-7. 